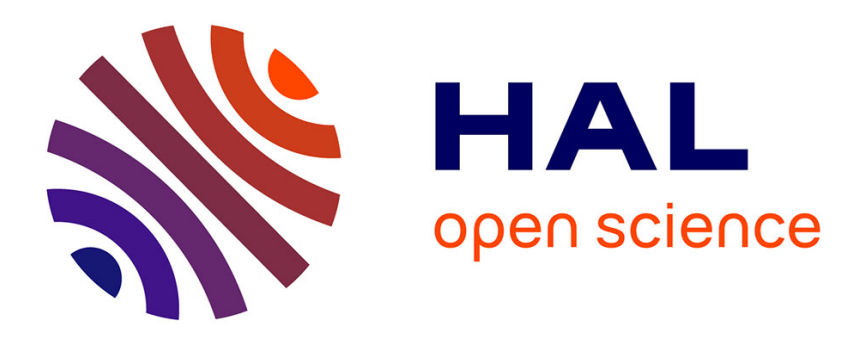

\title{
A systematic error of Michelson's type lambdameters
}

Jacques Vigué, B. Girard

\section{To cite this version:}

Jacques Vigué, B. Girard. A systematic error of Michelson's type lambdameters. Revue de Physique Appliquée, 1986, 21 (8), pp.463-465. 10.1051/rphysap:01986002108046300 . jpa-00245464

\section{HAL Id: jpa-00245464 https://hal.science/jpa-00245464}

Submitted on 1 Jan 1986

HAL is a multi-disciplinary open access archive for the deposit and dissemination of scientific research documents, whether they are published or not. The documents may come from teaching and research institutions in France or abroad, or from public or private research centers.
L'archive ouverte pluridisciplinaire HAL, est destinée au dépôt et à la diffusion de documents scientifiques de niveau recherche, publiés ou non, émanant des établissements d'enseignement et de recherche français ou étrangers, des laboratoires publics ou privés. 


\title{
REVUE DE PHYSIQUE APPLIQUÉE
}

Revue Phys. Appl. 21 (1986) 463-465

AOÛT 1986, PAGE 463

\author{
Classification \\ Physics Abstracts \\ $07.60 \mathrm{~L}-07.65$
}

\section{A systematic error of Michelson's type lambdameters}

\author{
J. Vigué and B. Girard \\ Laboratoire de Spectroscopie Hertzienne de l'ENS (associé au CNRS, U.A. 18), 24, rue Lhomond, 75231 Paris \\ Cedex 05, France
}

(Reçu le 4 mars 1986, révisé le 18 avril, accepté le 25 avril 1986)

\begin{abstract}
Résumé. - Nous décrivons ici une erreur systématique qui apparaît dans les lambdamètres de type Michelson lorsque le laser mesuré est balayé pendant la durée de mesure.
\end{abstract}

Abstract. - We describe here a systematic error that appears in Michelson's type lambdameters when the measured laser is tuned during the measurement.

We want to describe here a systematic error of a certain type of laser lambdameters which appears when the wavelength of the laser to be measured is swept during the measurement. These lambdameters are Michelson's type interferometers, with a moving mirror which is usually made of a cube corner (C.C.) $[1,2]$. The interferometer is illuminated by the counter-propagating beams of a reference laser (wavenumber $\sigma_{\mathrm{r}}$ ) and the laser to be measured (wavenumber $\sigma$ ).

To make a measurement, the C.C. is displaced, the optical path difference varying from $l_{1}$ to $l_{2}$ (we neglect here all the dispersion effects). The number of fringes observed on the reference laser is

$$
N_{\mathrm{r}}=\sigma_{\mathrm{r}}\left(l_{2}-l_{1}\right)
$$

and on the laser to be measured

$$
N=\sigma\left(l_{2}-l_{1}\right) \text {. }
$$

The ratio of the wavenumbers is deduced from the ratio of the number of fringes and the measured value $\sigma_{\mathrm{m}}$ of the wavenumber $\sigma$ of the unknown laser is

$$
\sigma_{\mathrm{m}}=\sigma_{\mathrm{r}} \frac{N}{N_{\mathrm{r}}}
$$

(various tricks can be used in order to measure the fractional part of $N$ and $N_{\mathrm{r}}$ ).

If, now, the laser wavenumber $\sigma$ is swept during the measurement, then equation (2) becomes

$$
\begin{aligned}
N & =\sigma\left(t_{2}\right) l_{2}-\sigma\left(t_{1}\right) l_{1} \\
& =\bar{\sigma}\left(l_{2}-l_{1}\right)+\left(\sigma\left(t_{2}\right)-\sigma\left(t_{1}\right)\right) \bar{l}
\end{aligned}
$$

where $t_{1}$ and $t_{2}$ are the initial and final time of the measurement and $\bar{\sigma}=\left(\sigma\left(t_{2}\right)+\sigma\left(t_{1}\right)\right) / 2, \quad \bar{l}=\left(l_{2}+\right.$ $\left.l_{1}\right) / 2$. Therefore we see that application of equation (3) gives a measured value

$$
\sigma_{\mathrm{m}}=\bar{\sigma}+\left(\sigma\left(t_{2}\right)-\sigma\left(t_{1}\right)\right) \frac{\bar{l}}{\left(l_{2}-l_{1}\right)}
$$

which differs from the " average wavenumber $" \bar{\sigma}$ by a corrective term. As $\bar{l}$ can be equal to several times $\left(l_{2}-l_{1}\right)$, this term may be equal to a few times the range $\Delta \sigma$ over which the laser wavenumber is swept during the measurement (i.e. between $t_{1}$ and $t_{2}$ ), and therefore the measured value $\sigma_{\mathrm{m}}$ may be outside the interval $\left[\sigma\left(t_{1}\right) ; \sigma\left(t_{2}\right)\right]$.

This systematic error is easy to detect because it depends on the relative sign of $\bar{l}$ and $\left(l_{2}-l_{1}\right)$; it changes sign with the sign of the mean path difference and with the direction of motion of the moving mirror. 
It depends also linearly on $\Delta \sigma$ and is more easily seen with rapid scans.

This systematic error can be roughly eliminated by a simple linear regression of the results obtained over several back and forth motions of the C.C., as the average of the error is zero provided that the measurements are made at the same points in the two ways of motion, for which errors are opposite if the sweep of the laser is linear (this compensation being true even if the accessible range of path differency is not symmetric around zero). But this correction can be effective only if no measurement is lost because of electronic problems, or mode hops. We discuss below a practical example of the correction of this error.

Another feature of this systematic error appears when we make several consecutive measurements during the same motion of the cube corner : provided that $\frac{\mathrm{d} \sigma}{\mathrm{d} t}$ and $\frac{\mathrm{d} l}{\mathrm{~d} t}$ are independent of time, the $p$ th measurement is related to the first by the relation

$$
\left(\sigma_{\mathrm{m}}\right)_{p}=\left(\sigma_{\mathrm{m}}\right)_{1}+2 p \Delta \sigma
$$

as the « average wavenumber » during the $p$ th measurement is

$$
\bar{\sigma}_{p}=\bar{\sigma}_{1}+p \Delta \sigma
$$

therefore, the apparent variation of the wavenumber during a single motion of the cube corner is twice its real variation (experimentally determined by an interpolation of the measurements obtained during several back and forth motions of the cube corner).

\section{Experimental evidence.}

Our lambdameter is a simple Michelson interferometer; the path difference accessible range is approximately $l=-10$ to $+24 \mathrm{~cm}$ (the asymmetry is due to mechanical design). The reference laser is a commercial HeNe laser (Spectra physics model 196-2), one mode is selected and stabilized using the technique described by Bennett [3] with a precision of the order of $20 \mathrm{MHz}$. The laser to be measured is a homemade [4] cw monomode dye laser working here in the range $700-780 \mathrm{~nm}$ with $\mathrm{LD} 700$ pumped by a $\mathrm{K}_{\mathrm{r}}^{+}$ laser. Using electronic multiplication of fringe pattern [1] (by a factor of 100), we are able to get a precision of lecture of $10^{-3} \AA$ and an absolute accuracy of the same order by counting $N=63282$ fringes of the unknown laser (i.e. for $\lambda=750 \mathrm{~nm}, l_{2}-l_{1}=$ $4,8 \mathrm{~cm}$ and a time interval $t_{2}-t_{1} \simeq 0,8 \mathrm{~s}$ ), giving a multiplying factor $\frac{\bar{l}}{\Delta l}$ varying from -2.1 to +5.0 . The measurements are fed to a computer which makes the various corrections necessary to get the exact wavelength and wavenumber.

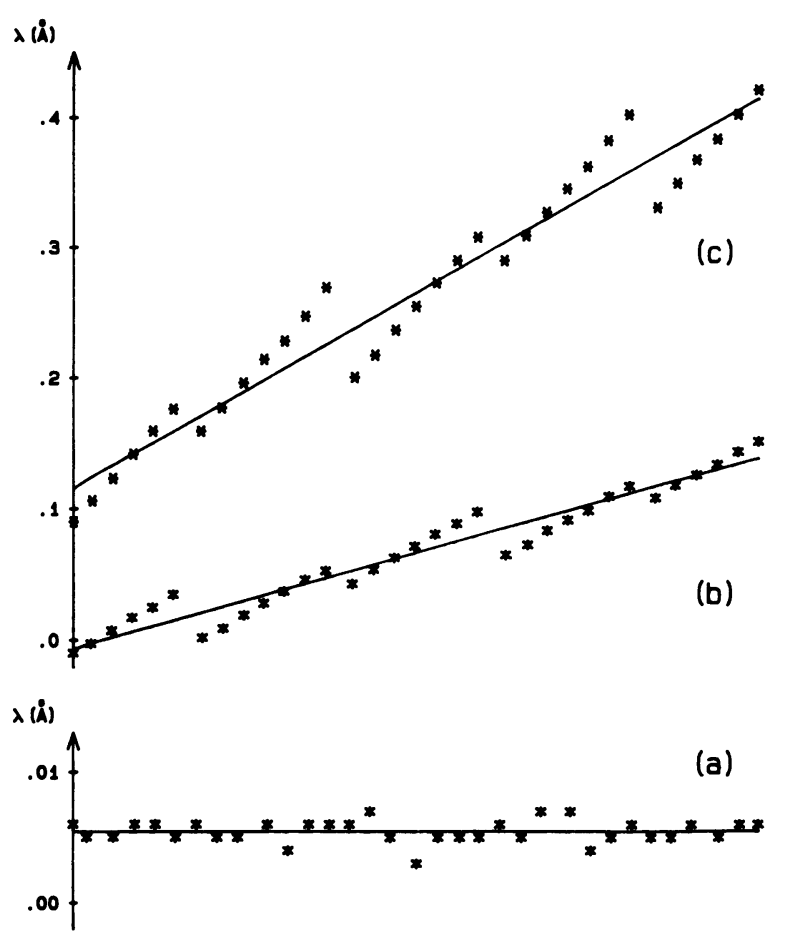

Fig. 1. - Three different sets of measurements as a function of time (each measurement lasts $0.8 \mathrm{~s}$ ). (a) Laser wavelength is constant (R.M.S. deviation of the measurements equal $0.8 \times 10^{-3} \AA$ ); note the expanded scale. (b) and (c) laser wavelength is swept continuously at $5 \times 10^{-3}$ and $10^{-2} \AA / \mathrm{s}$ respectively. The pattern is in good agreement with theory. The full curves are linear interpolations of the measurements.

Figure 1 shows the values of measured wavenumbers versus time for 3 different conditions. In case a, the frequency of the laser is constant (within jitter which is less than $50 \mathrm{MHz}$ ) ; the excellent reproducibility of the measurement is well shown in this case. In case b and $\mathrm{c}$, the laser wavelength is swept continuously and regularly at $5 \times 10^{-3} \AA / \mathrm{s}$ and $10^{-2} \AA / \mathrm{s}$ respectively.

The measured values present a sawtooth pattern, characteristic of the systematic error : every 7 measurements, the error changes sign because the cube corner sense of motion is reversed and the discontinuity observed is in good agreement with the value deduced from equation (5). During these 7 consecutive measurements in the same sense of motion of the cube corner, the local slope of the measured values versus time is effectively twice the mean slope over the whole sweep.

\section{Practical application.}

We have used our lambdameter to measure the positions of the lines of the excitation spectrum of IF molecule (B-X system). The laser wavenumber was scanned at a speed of $5 \times 10^{-3} \mathrm{~cm}^{-1} / \mathrm{s}$ and the lambdameter was used as described above and with the same values of the parameters. In these conditions the maximum systematic error is $1.9 \times 10^{-2} \mathrm{~cm}^{-1}$ and the r.m.s. 
deviation of the linear regression of the measured wavenumbers is $1.0 \times 10^{-2} \mathrm{~cm}^{-1}$. We have recorded 20 times the same spectrum containing 10 lines (near $13200 \mathrm{~cm}^{-1}$ ) (this was done on the same day and has taken a time period of the order of 5 hours). The r.m.s deviation of the 20 measured positions was calculated for each of these lines and found in the range $6 \times$ $10^{-4}-11 \times 10^{-4} \mathrm{~cm}^{-1}$ (these values have to be compared to the linewidth which is closed to $4 \times$ $10^{-2} \mathrm{~cm}^{-1}$ ). These r.m.s deviations of the order of $10^{-3} \mathrm{~cm}^{-1}$ give an idea of the reproducibility of the lambdameter and of the efficiency of the linear regression procedure used to correct the systematic error discussed here.

\section{Conclusion.}

In this paper, we have shown the existence of a systematic error of Michelson's type lambdameter. Moreover, we have shown in a practical case that it can be efficiently corrected by a simple linear regression of the measurements obtained over several back and forth motions of the cube corner.

\section{Acknowledgments.}

We are pleased to thank A. Brillet, J. Cachenaut and F. Stoeckel for their suggestions in the design of our lambdameter and G. Trenec, A. Clouqueur, J. C. Bernard for their help in its construction.

\section{References}

[1] Hall, J. L. and Lee, S. A., Appl. Phys. Lett. 29 (1976) 367.

[2] Kowalski, F. V., Hawkins, R. T. and Shawlow, A. L., J. Opt. Soc. Amer. 66 (1976) 965.

Kowalski, F. V., Teets, R. E., Demtroder, W. and Schawlow, A. L., J. Opt. Soc. Amer. 68 (1978) 1611 ;

Cachenaut, J., Man, C., Cerez, P., Brillet, A., Stoeckel, F., Jourdan, A., Hartmann, F., Rev. Phys. Appl. 14 (1979) 685;
Monchalin, J. P., Kelly, M. J., Thomas, J. E., Kurnit, N. A., SzöKe, A., Zernike, F., Lee, P. H., Javan, A., Appl. Opt. 20 (1981) 736;

Castell, R., Demtröder, W., Fischer, A., Kullmer, R., WeickenmeIer, H. and WiCKert, K., Appl. Phys. B 38 (1985) 1.

[3] Bennett, S. J., Ward, R. E. and Wilson, D. C., Appl. Opt. 12 (1973) 1406.

[4] Biraben, F., Labastie, P., Optics Commun. 41 (1982) 49 ; and Private Communication. 